\title{
Diazepam and memory: Support for a duplex model of memory
}

\author{
STEVEN P. MEWALDT \\ Marshall University, Huntington, West Virginia \\ and \\ JAMES V. HINRICHS and M. M. GHONEIM \\ University of Iowa, Iowa City, Iowa
}

\begin{abstract}
In three experiments, the hypothesis that diazepam (Valium) selectively impairs the transfer of information from short-term to long-term memory was supported by differences between placebo and drugged subjects in effects of item difficulty, serial position (primacy-recency), and list length. In Experiment 1, diazepam reduced recall in the primacy portion of the serial position function, but produced no performance difference in the recency component. Recall decreased in placebo subjects as item difficulty increased, but drugged subjects were relatively uaffected by manipulation of difficulty. In Experiments 2 and 3, subjects treated with diazepam exhibited smaller gains in immediate recall with increasing list length than placebo controls. Retrieval of words learned before drug administration was not impaired by diazepam; in fact, it was significantly enhanced relative to control performance. The results add further support to the distinction between short- and long-term memory.
\end{abstract}

Since the 1960s, a dominant approach to learning and memory processes has been to divide memory into two components: a limited-capacity, short-term-memory (STM) store and a large-capacity, long-term-memory (LTM) store (see Atkinson \& Shiffrin, 1968, 1971, and Waugh \& Norman, 1965). Although there are a number of criticisms of the duplex model that have forced modifications of the theory (for a review, see Klatzky, 1980), it continues to be a comprehensive and useful approach to the analysis of human memory. The present paper is intended to illustrate the usefulness of the model in the growing area of cognitive psychopharmacology and also to illustrate how pharmacological manipulations can be utilized to investigate specific human memory processes.

The literature on cognitive psychopharmacology contains many studies of drugs with similar and specific detrimental effects on memory (e.g., Birnbaum \& Parker, 1977; Crow \& Grove-White, 1973; Darley, Tinklenberg, Roth, Hollister, \& Atkinson, 1973; Ghoneim \& Mewaldt, $1975,1977)$. Illustrative of these drugs is diazepam (Valium), until recently the most often prescribed drug in the world. The specific memory impairment produced by diazepam has been well demonstrated.

This research was supported by NIMH Grant MH 35324. A portion of this paper was presented at the Psychonomic Society meeting in Minneapolis, November 12, 1982. We thank Nancy Fallis and Janis L. Berie for their assistance. Requests for reprints should be sent to Steven P. Mewaldt, Department of Psychology, Marshall University, Huntington, West Virginia 25701 .
For example, diazepam impairs acquisition of serial, paired-associate, and free-recall lists, but does not affect performance on a Brown-Peterson distractor task or a short memory span task, or, apparently, hinder retrieval of previously acquired information (see Clarke, Eccersley, Frisby, \& Thornton, 1970; Dundee \& Pandit, 1972; Ghoneim \& Mewaldt, 1975, 1977; Hinrichs, Mewaldt, Ghoneim, \& Berie, 1982). We have interpreted these data as suggesting that diazepam leaves STM and retrieval from LTM intact, while greatly impeding the transfer of information from STM to LTM. According to the duplex model, without this transfer or consolidation of information, new learning cannot be permanently encoded. The present paper provides several tests of this STM-LTM transfer impairment interpretation of the action of diazepam on memory function.

One test of the transfer hypothesis is provided by an analysis of the serial position curve in free recall. According to common arguments, recall of the last few items (recency items) in a free-recall list primarily reflects STM retention, whereas recall of the beginning and the middle of the list primarily reflects LTM retention (e.g., Atkinson \& Shiffrin, 1971; Glanzer \& Cunitz, 1966) ${ }^{1}$ Consequently, if diazepam blocks LTM acquisition while leaving STM intact, one would expect that drugged subjects would recall fewer items than nondrugged subjects at the beginning and middle portions of the list, but would recall as many recency items as nondrugged subjects would.

A second method of evaluating the memory transfer hypothesis is to test the interaction of diazepam with 
variables that should differentially affect the STM and LTM components of memory. Glanzer and Cunitz (1966) conducted an elaborate set of experiments to examine such variables. They found that delay between presentation and recall significantly reduced retention of recency items (i.e., STM items) but had little influence on earlier (LTM) items. On the other hand, slowing the rate of presentation significantly improved LTM performance but did not change retention of recency items. Similarly, Sumby (1963) found that increasing the frequency or meaningfulness of the stimulus words improved LTM performance but had little effect on STM retention.

Experiment 1 manipulated rate of presentation, delay of recall, and item difficulty to test the STM-LTM transfer interpretation of the effect of diazepam. The immediate and delayed recall of four 32-item free-recall lists was analyzed. The lists were presented at a fast or a slow rate (1 or $4 \mathrm{sec} /$ item) and consisted of relatively hard or easy words. It was predicted that the subjects who received diazepam would show little or no decrease in recall of material from STM, but that large deficits would be found in LTM recall. Furthermore, it was predicted that manipulations intended to improve LTM acquisition would be relatively less effective for the drugged subjects.

\section{EXPERIMENT 1}

\section{Method}

Subjects. Twenty-four healthy, paid volunteers ( 12 males and 12 females) were recruited through a local newspaper advertisement to serve as subjects. Their ages ranged from 18 to 30 years. At an initial interview, a detailed medical history was obtained, and the subjects were informed of the general nature of the drugs and tests to be employed in the study. The subjects were assigned randomly to either drug (diazepam) or placebo treatment and were tested in a double-blind fashion. There were 12 subjects in each of the two treatment conditions, with an equal number of males and females per condition.

Treatments. Diazepam or a placebo was administered orally in identical gelatin capsules. All subjects received three capsules. The dosage of diazepam was weight dependent, approximately $.3 \mathrm{mg} / \mathrm{kg}$. Combinations of three differently sized capsules $(2,5,10 \mathrm{mg})$ were used to administer the calculated dosage; in all cases, the dose received was within $10 \%$ of the nominal value.

Procedure. The subjects were tested in groups ranging in size from five to seven individuals. Four 3-h sessions were required to complete the study; two sessions were conducted in the morning from 9:00 a.m. to 12:00 noon, and two sessions were conducted in the afternoon from 1:00 p.m. to 4:00 p.m. Approximately one-half of the subjects in each test group were drawn from each of the two treatment conditions. The subjects were advised to get a good night's sleep and to abstain from food and beverages at least $4 \mathrm{~h}$ prior to the testing session.

The tests employed and their order of administration were constant. Approximately $1 \mathrm{~h}$ prior to drug administration, the subjects reported to the laboratory, received general instructions, and signed consent forms. They then practiced the various tasks employed in the experiment. Before performing the freerecall task of interest here, the subjects completed mood-evaluation forms and a series of cognitive problem-solving tasks, which were included for pilot purposes. Fifteen minutes prior to drug administration, the practice free-tecall task was presented. The subjects listened to a series of 32 nouns selected from the Paivio, Yuille, and Madigan (1968) norms as being of intermediate difficulty (i.e., they did not meet the criteria for "easy" and "hard" words described below). The list was presented at a rate of 1 word $/ 2$ sec. Immediately following presentation of the last word, the subjects were given 2 min to write, in any order, as many of the words as they could recall.

The postdrug immediate free-recall test began 45 min after drug administration. The subjects listened to four uncategorized lists of 32 nouns presented by a cassette recorder. All of the nouns were selected from the Paivio et al. (1968) norms. Two of the lists were composed of 32 "easy" words, defined by ratings of imagery and concreteness greater than 5.0, ratings of meaningfulness greater than 5.97 (Paivio et al., 1968), and frequencies greater than 49 per million according to Thorndike and Lorge (1944). The remaining two lists were composed of 32 "hard" words, defined by ratings of imagery and concreteness less than 5.0 , ratings of meaningfulness less than 5.97 , and frequencies less than 49 and greater than 1 per million. For each list type ("easy" and "hard"), one list was presented at a slow rate, 1 word $/ 4 \mathrm{sec}$, and the other was presented at a fast rate, 1 word/ $\mathrm{sec}$. The order of the four lists for each testing session was counterbalanced.

Immediately after each list had been presented, the subjects were given $2 \mathrm{~min}$ for written free recall of the words. Approximately $15 \mathrm{~min}$ after recall of the last list, during which time the subjects were occupied with an unrelated problem-solving task, the subjects were asked to write, in any order, as many of the words as they could remember from all five lists (i.e., four postdrug lists and one predrug practice list). Five minutes were permitted for this delayed free recall.

\section{Results}

Immediate free recall. Recall of the 32-word practice list was analyzed to assure that the two groups were of equal ability prior to drug ingestion. There were no significant differences between the groups $[t(22)=1.12$, $p>.20]$. The subjects in the placebo group recalled a mean of 10.7 words correctly; the subjects who were later treated with diazepam recalled 12.3 words.

Recall of the four postdrug lists was analyzed in a five-way analysis of variance, with rate of presentation, difficulty, and serial position as within-subject factors and sex and drug treatment as between-subject factors. In order to add stability to the serial position scores, data from blocks of four serial positions were collapsed into one score. In order to simplify the following presentation, only effects involving the drug manipulation or those needed to verify the effectiveness of a variable are reported.

As expected, there was a significant main effect for drug condition $[F(1,20)=10.32, \mathrm{MSe}=3.07, \mathrm{p}<.01]$. The subjects who received diazepam averaged only $22 \%$ (7.2 items) correct across all conditions, whereas the placebo subjects averaged 33\% (10.4 items) correct. There was a significant interaction between drug condition and serial position $[F(1,140)=2.35, \mathrm{MSe}=.83$, $\mathrm{p}<.01$; see Figure 1]. As predicted, the drugged subjects displayed decreased recall across the whole serial position curve except at the recency portion of the curve, at which the performance of the groups was virtually identical. Also apparent in Figure 1 are the significant drug condition $x$ item difficulty interaction $[F(1,20)=$ 


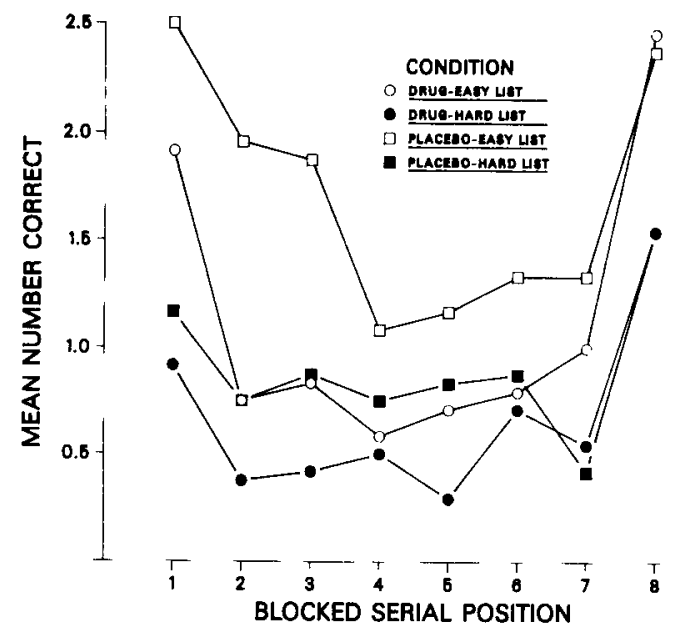

Figure 1. Experiment 1: Immediate free recall as a function of drug condition, list difficulty, and blocked serial position.

8.50, MSe $=.63, \mathrm{p}<.01]$ and the item difficulty $\mathrm{x}$ serial position interaction $[\mathrm{F}(1,140)=3.13, \mathrm{MSe}=.83$, $\mathrm{p}<.01]$. High-imagery, high-frequency words were recalled better overall, but the difference was most pronounced at the early, or LTM, portion of the serial position curve. Planned comparisons indicated that, whereas the effect of list difficulty was quite pronounced in the placebo subjects $(p<.01)$, the difference between the easy and the hard lists was not significant for the drug group $(\mathrm{p}>.05)$. Finally, although rate of presentation did interact with serial position as expected $[F(7,140)=2.65, \mathrm{MSe}=.67, \mathrm{p}<.05]$ (i.e., there was a rate effect on early, or primacy, items and no effect on the final, or recency, items), there was no significant interaction between drug condition and rate of presentation $(\mathrm{p}>.1)$.

Delayed free recall. The delayed-free-recall results were examined in two separate analyses. The first analyzed recall of the four lists learned following drug administration and employed the same factors as the analysis reported above. This analysis revealed that, as in immediate recall, the subjects who received diazepam performed much more poorly than did the placebo subjects $[\mathrm{F}(1,20)=14.04, \mathrm{MSe}=2.87, \mathrm{p}<.001]$. Of a possible 132 words, the drugged subjects recalled an average of 10.8 words correctly, whereas the placebo subjects recalled a mean of 25.5 words. However, unlike in immediate recall, there was no interaction between drug condition and serial position $(p>.05)$. The relatively normal recall exhibited by the drugged subjects for recency items in the immediate-recall task had disappeared in delayed recall, as evidenced by the fact that these subjects displayed poorer performance across the whole serial position curve. In addition, the interaction between drug condition and item difficulty was significant $[F(1,20)=10.98, \mathrm{MSe}=.92, \mathrm{p}<.01]$. Follow-up analyses indicated that easy words were recalled better by both the drugged and the nondrugged subjects $(\mathrm{p}<.05)$, but the difference was larger in the placebo group. Finally, although the drug condition $x$ presentation rate interaction was in the predicted direction, it was not significant $(.1<\mathrm{p}<.05)$

The second analysis of delayed free recall included performance on the practice list. Because this list differed in both difficulty and presentation rate from the postdrug lists, these factors were not included in the analysis. Instead, the position of the list in presentation, (i.e., practice or first postdrug list, second postdrug list, etc.) was included as a factor. Of course, addition of the practice-list data did not remove the overall drug effect reported above $[\mathrm{F}(1,20)=5.99, \mathrm{MSe}=2.59, \mathrm{p}<.05]$. However, this analysis revealed an interesting interaction between drug condition and presentation position of the list from which the words were recalled $[F(4,80)$ $=6.01, \mathrm{MSe}=1.73, \mathrm{p}<.01]$. Follow-up analyses on this interaction indicated that, within each drug condition, when collapsed across the rate and difficulty variables, there were no significant differences in recall of the four postdrug lists. However, the subjects who received diazepam recalled significantly more items from the practice list than did the placebo subjects ( 7.0 vs. 2.4 ) $(p<.01)$, and the drugged subjects recalled significantly fewer items from the postdrug lists than did the control subjects $(2.7$ vs. 6.4$)(\mathrm{p}<.05)$.

\section{Discussion}

Several aspects of the data strongly support the hypothesis that diazepam impairs memory by reducing the transfer of information from STM to LTM, while leaving other memory processes relatively intact. First, although the diazepam subjects generally recalled less than did the placebo subjects, analysis of the serial position curve indicated that it was only on the early (LTM) items of the list that the drugged subjects performed poorly. Their recall of the last few items of the list (STM component) was virtually identical to that of their nondrugged controls. In addition, when the contribution of STM was eliminated, as in delayed free recall, the performance of the drugged subjects fell further below that of the placebo subjects. Without the benefit of recall from STM, the previously unimpaired recall of recency items by the drugged subjects disappeared; that is, they displayed poorer recall than did the control subjects across the whole serial position curve. These data strongly suggest that it is a LTM process that is being disrupted by the drug.

Further support was found in the interaction between drug condition and item difficulty. According to Sumby (1963), increasing the frequency or meaningfulness of a list's items should improve LTM performance but should have little influence on STM recall. We found that the placebo subjects displayed much better performance as item difficulty was decreased, whereas the diazepam subjects were relatively unaffected by changes in item difficulty. These data seem to indicate that, for both the drug and the placebo subjects, "easy" words 
were more easily recalled from LTM than were "hard" words; however, since the diazepam subjects placed relatively few items in LTM, the effect was much smaller in the drug group. Since rate of presentation is also supposed to influence primarily LTM processes, it was anticipated that rate would interact similarly with drug condition. However, although slowing the presentation rate did improve LTM performance, and the direction of the interaction with drug condition was as predicted, it was not significant.

The delayed-free-recall data also strongly imply that it is the acquisition, not the retrieval, of information by LTM that is impaired by the drug. It was only for recall of words learned after drug ingestion that the subjects who received diazepam displayed deficits. Not only were the drugged subjects not impaired on recall of items learned prior to drug administration, but they actually recalled these items significantly better than did their placebo counterparts. If retrieval processes were impaired by diazepam, one would expect that recall of lists learned both before and after drug administration would be adversely affected. Instead, we found that material learned just prior to drug administration was actually recalled better by the diazepam group than by the placebo group.

The observation that subjects who receive diazepam recall predrug material better than do placebo subjects is consistent with data from Clarke et al. (1970). More recently, Parker, Birnbaum, Weingartner, Hartley, Stillman, and Wyatt (1980) and Parker, Morihisa, Wyatt, Schwartz, Weingartner, and Stillman (1981) found that subjects who viewed a series of scenic slides just before drinking alcohol later remembered the slides significantly better than did subjects who received a placebo. Parker et al. (1981) concluded that this retrograde enhancement of memory is due to a facilitation of the trace consolidation process by the alcohol. Although their interpretation provides an explanation for the present data, the present results may also be explained easily by an interference mechanism: When recalling the practice list, the drugged subjects should have experienced much less retroactive interference than did the placebo subjects because the drugged subjects had learned so little of the postdrug material. As a result, recall of the predrug list by the diazepam subjects would be expected to be better than that of the placebo controls.

\section{EXPERIMENT 2}

Experiment 2 further evaluated the impact of diazepam on STM-LTM transfer by varying list length in a free-recall task. STM is presumed to have a limited capacity variously estimated to be three to seven items. Consequently, as the length of a list is increased, the relative proportion of items that must be transferred into LTM for retention must also increase. If diazepam impedes the transfer of information into LTM, but leaves STM intact, one would expect that drugged subjects would show proportionally larger performance deficits for each increment in list length. In the extreme, if diazepam totally blocked transfer to LTM, drugged subjects would be limited to recalling only the items held in STM, regardless of the list length. In any case, the decreasing contribution of STM to overall performance as list length increases should produce a significant drug condition $\mathrm{x}$ list length interaction. This prediction was tested in Experiment 2.

\section{Method}

Twenty-four healthy, paid volunteers (12 males and 12 females) were recruited as before. All general details of subject treatment were the same as in Experiment 1. The subjects were tested in groups of five to seven individuals, at one of four sessions. Two sessions were conducted from 9:00 a.m. to 12:00 noon, and two sessions were conducted from 1:00 p.m. to 4:00 p.m. As in Experiment 1, the diazepam or placebo was administered orally in a dosage of $.3 \mathrm{mg} / \mathrm{kg}$. Again, the subjects completed the mood-evaluation form and pilot cognitive tests employed in Experiment 1.

Five minutes prior to drug administration, the subjects were given and were asked to recall a 32-word practice free-recall list. Fifty minutes after drug administration, the subjects viewed four uncategorized lists of words. All lists were presented as slides on a front-projection screen. The postdrug lists consisted of words that had been selected from Paivio et al. (1968) and were classified as "easy" words, whereas the practice list was of intermediate difficulty, as defined in Experiment 1 . The four word lists varied in length $(16,24,32$, and 40 words). Each of the lists was presented at a rate of $2 \mathrm{sec} /$ word, with timing controlled by a Wollensach sync-mode cassette tape recorder. Half of the subjects were presented with the four lists in ascending order of length: $16,24,32$, and 40 . The remaining subjects viewed the lists in descending order of length: $40,32,24$, and 16 .

Immediately after each list had been presented, the subjects were given 2 min to write, in any order, as many of the words as they could remember from the most recently presented list. After all four lists had been presented and tested, and after an additional interval of approximately $20 \mathrm{~min}$, during which the subjects completed a number-learning sequence and a moodevaluation and cognitive booklet, the subjects were asked to write, in any order, as many of the words as they could remember from the five lists presented earlier that session (i.e., four postdrug and one predrug practice list). Five minutes were permitted for delayed free recall.

\section{Results}

Immediate free recall. The results of the immediatefree-recall task were analyzed in a $2 \times 2 \times 4$ analysis of variance, with drug condition and sex as between-subject factors and sequence length as a within-subject factor. The results indicated that, once again, diazepam impaired recall $[\mathrm{F}(1,20)=4.85, \mathrm{MSe}=34.66, \mathrm{p}<.05]$. The subjects who received diazepam recalled a mean of 8.2 words per list, whereas the placebo subjects recalled a mean of 10.9 words. As would be expected, there was also a significant main effect for sequence length $[\mathrm{F}(3,60)=9.22, \mathrm{MSe}=4.17, \mathrm{p}<.001]$. The total number of words recalled increased as list length increased. Finally, although the predicted interaction between drug condition and list length was not significant $(\mathrm{p}>.1)$, there was a significant sex $x$ drug condition $x$ length interaction $[F(3,60)=3.46, p<.05]$. 
As is apparent in Figure 2, for females, the interaction between drug condition and list length was significant $(p<.05)$, the result of an increased difference between drug and nondrug performance as the lists became longer. For male subjects, on the other hand, the relationship was reversed. In fact, for males, the difference between drug and nondrug performance was not significant at the 32- and 40-item lengths $(p>.05)$.

Delayed free recall. Delayed recall of the lists learned following drug administration was analyzed in the same manner as were the immediate-recall results. Again, there was a significant main effect for drug condition $[F(1,20)$ $=14.56, \mathrm{MSe}=17.64, \mathrm{p}<.001]$. Diazepam subjects recalled an average of 12.9 words correctly, whereas the placebo subjects recalled an average of 26.0 correct. However, although the pattern of results was virtually identical to that for immediate free recall, in delayed recall, neither the drug condition $x$ length interaction nor the sex $\mathrm{x}$ drug condition $\mathrm{x}$ length interaction was significant $(\mathrm{p}>.1)$.

The delayed-free-recall results were also analyzed with performance on the practice list included. In this analysis, performance on the various list lengths was collapsed so that the data could be analyzed for list presentation position. Of course, the drug subjects still recalled significantly less overall than did the placebo subjects $[F(1,20)=10.03, \mathrm{MSe}=1.42, p<.01]$. However, as in Experiment 1, there was a significant drug condition $\mathrm{x}$ list position interaction $[\mathrm{F}(4,80)=6.38$, MSe $=$ $.90, \mathrm{p}<.001]$. The interaction was similar to that in Experiment 1; that is, the subjects who received diazepam recalled the practice list significantly better than did the placebo subjects (4.8 vs. 2.0 words correct, respectively) $(\mathrm{p}<.01)$, whereas the placebo subjects recalled the postdrug lists significantly better than did the drugged subjects (6.5 vs. 3.2 words per list, respectively) $(\mathrm{p}<.01)$.

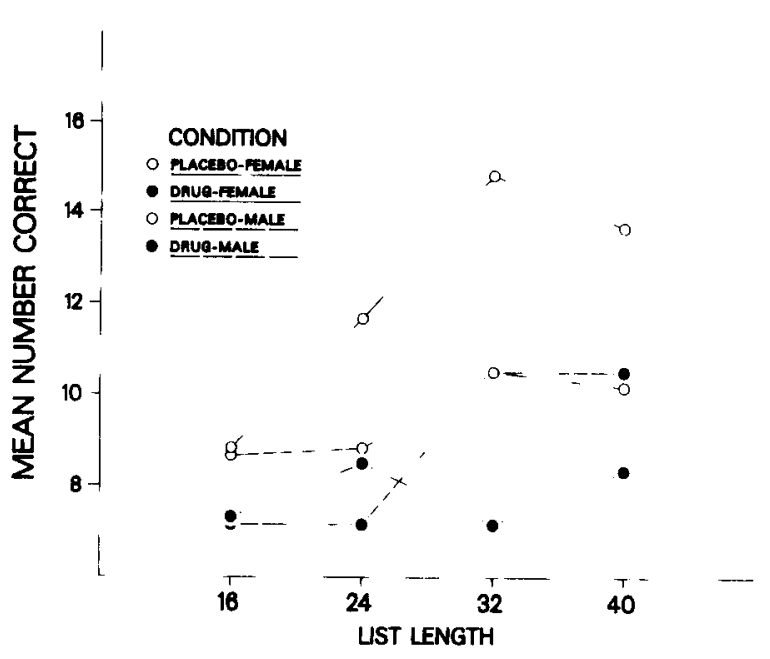

Figure 2. Experiment 2: Immediate free recall as a function of drug condition, sex, and list length.

\section{Discussion}

Diazepam again had a pronounced effect on learning. The subjects who received diazepam generally experienced a $30 \% .50 \%$ reduction in performance, compared with the control subjects. However, the effect of the listlength variable was ambiguous. Females who received diazepam recalled a constant $7-8$ words per list, regardless of sequence length, whereas female control subjects generally recalled more words as the length of the list increased. Consequently, as predicted, drug effects increased with sequence length. However, the performance of male subjects was somewhat baffling. As the lists grew longer, the drug subjects actually increased their recall more than did the placebo subjects. At the 32- and 40-item list lengths, the differences between drug and nondrug subjects were not significant. In previous research, we had always observed a great deal of individual variability in subjects' responses to diazepam, but had never observed any consistent sex difference. Consequently, since Experiment 1 demonstrated a reliable performance difference for a 32-item list for both male and female subjects, we attribute the unusual pattern of results in the present study to a higher than typical proportion of drug-resistant males being assigned to the experimental group.

Although the effects of list length on drugged subjects may be somewhat unclear, the effects of diazepam on delayed free recall in the present study were not ambiguous; they perfectly replicate the findings of Experiment 1. The subjects who received diazepam recalled the predrug list better than did the placebo subjects, whereas the reverse was true for the lists learned following drug administration. Once again diazepam impaired only the acquisition of new information-it did not impair retrieval of old memories. In fact, it again enhanced recall of material learned immediately before drug administration.

\section{EXPERIMENT 3}

In Experiment 2, female subjects performed as predicted; that is, the difference between the recall of drugged subjects and that of placebo subjects increased as the memory load (sequence length) increased. For male subjects, on the other hand, the relationship was reversed. Because the result was inconsistent with all previous data cited earlier, including those of Experiment 1 , we repeated the list-length manipulation to determine whether the unusual sex effect could be replicated.

\section{Method}

Forty-eight subjects ( 24 males and 24 females) were recruited and treated as before. Diazepam or a placebo was administered in identical capsules at a dosage of $.3 \mathrm{mg} / \mathrm{kg}$. All subjects were tested in groups of six individuals, in afternoon sessions.

The manipulation reported here was conducted at the end of an unrelated experiment. Consequently, all subjects had completed a series of coordination and problem-solving tasks prior 
to the list-length task. In addition, all subjects had learned and immediately recalled one 24 -word practice list prior to drug administration, and half the subjects had similarly learned and recalled another 24-word list $60 \mathrm{~min}$ after drug administration. These lists were tested in a delayed-recall and recognition test $2 \mathrm{~h}$ after drug administration.

The subjects began to learn the lists 145 min after drug administration. Although this time is somewhat later than that employed in Experiments 1 and 2, prior research had indicated that memory performance following a $.3-\mathrm{mg} / \mathrm{kg}$ oral dose of diazepam does not recover until 4.5 to $5.5 \mathrm{~h}$ after drug administration (Ghoneim, Hinrichs, \& Mewaldt, in press). All subjects learned and immediately recalled one uncategorized word list at each of three lengths: 12,24 , and 36 items. The details of the experiment were similar to those of Experiment 2. The words were presented at a $2-\mathrm{sec}$ rate. In each list, half the words were "easy" and half were "hard," as defined in Experiment 1. Because the 24-word list was important in the early part of the experiment, it was presented first to all subjects. The order of the subsequent 12- and 36-word lists was counterbalanced. Immediately after the presentation of each list, the subjects were given $2 \mathrm{~min}$ for free recall of the items. Twenty-five minutes later, the subjects were given $3 \mathrm{~min}$ for delayed free recall of the items from all three lists.

\section{Results and Discussion}

The results were analyzed in an analysis of variance, with word difficulty ("easy" or "hard") and sequence length $(12,24,36)$ as within-subject factors and drug, sex, and number of prior lists learned (1 or 2) as betweensubject factors. Because of the large number of factors in the design, alpha was set at .01 . Once again, only those effects involving the drug, and thus relevant to this discussion, are reported. Analysis of immediate free recall indicated that drugged subjects learned significantly less than placebo subjects $[F(1,40)=69.54$, $\mathrm{MSe}=3.89, \mathrm{p}<.001]$, which showed that diazepam still affected performance almost $2.5 \mathrm{~h}$ after administration. Second, there was a significant interaction between item difficulty and drug condition $[\mathrm{F}(2,80)=7.42$, $\mathrm{MSe}=2.50, \mathrm{p}<.01]$. This interaction can be found in Table 1. Follow-up analyses indicated that, although the effect of word difficulty was significant in both the placebo and the drug groups $(p<.01)$, the effect was much larger in the placebo group. Of greater interest here, the interaction between drug condition and se- quence length was significant $[\mathrm{F}(2,80)=11.30, \mathrm{MSe}=$ $1.87, \mathrm{p}<.001]$. This interaction can also be found in Table 1. As in Experiment 2, the memory impairment produced by diazepam increased as the memory load, or list length, increased. Follow-up analyses indicated that the number of words recalled increased in both the drug and the placebo groups as list length increased. However, at all lengths, the diazepam subjects recalled significantly less than did the placebo subjects $(p<.01$ in all cases), and the difference in performance between the two groups increased as list length increased. In addition, the unusual drug condition $\mathrm{x}$ sex $\mathrm{x}$ list length interaction observed in Experiment 2 did not approach significance in Experiment $3(\mathrm{~F}<1)$.

The results for delayed free recall of the three lists are displayed in Table 1. An analysis of variance employing the same factors as above indicated a large main effect for drug condition $[F(1,40)=260.68$, MSe $=2.55$, $\mathrm{p}<.001]$. In addition, there was a significant drug condition $x$ word difficulty interaction $[F(1,40)=14.39$, $\mathrm{MSe}=1.18, \mathrm{p}<.001]$, but the interaction between drug condition and list length was only marginally significant $[\mathrm{F}(2,80)=4.73, \mathrm{MSe}=2.88, \mathrm{p}<.05]$. Both interactions follow the same pattern as in immediate free recall. Finally, there was a significant drug condition $\mathrm{x}$ word difficulty $x$ sex interaction $[F(1,40)=10.58$, $\mathrm{p}<.01]$. Although for both male and female subjects the difference between recall of "easy" and "hard" words was larger in the placebo than in the drug group, this difference was larger for male subjects overall. As with immediate free recall, sex did not interact with list length and drug condition $(F<1)$.

The results of Experiment 3 suggest that male and female subjects who receive diazepam do not respond differently in recall of various length sequences. Consequently, Experiments 2 and 3 together strongly support the prediction that, the larger the memory load placed on the subjects, drugged subjects should display a relatively greater memory deficit. Specifically, it is suggested that, as the sequence length increases beyond the memory span, the relative contribution of STM to total recall declines. Consequently, if diazepam impairs only the

Table 1

Immediate and Delayed Free Recall in Experiment 3: Mean Number Correct and Corresponding Standard Errors as a Function of Sequence Length and Drug Condition

\begin{tabular}{|c|c|c|c|c|c|c|c|c|c|c|c|c|}
\hline \multirow[b]{4}{*}{ Drug Condition } & \multicolumn{6}{|c|}{ Easy Words } & \multicolumn{6}{|c|}{ Hard Words } \\
\hline & \multicolumn{6}{|c|}{ List Length } & \multicolumn{6}{|c|}{ List Length } \\
\hline & \multicolumn{2}{|c|}{12} & \multicolumn{2}{|c|}{24} & \multicolumn{2}{|c|}{36} & \multicolumn{2}{|c|}{12} & \multicolumn{2}{|c|}{24} & \multicolumn{2}{|c|}{36} \\
\hline & Mean & SE & Mean & SE & Mean & $\mathrm{SE}$ & Mean & SE & Mean & SE & Mean & SE \\
\hline \multicolumn{13}{|c|}{ Immediate Recall } \\
\hline $\begin{array}{l}\text { Placebo } \\
\text { Diazepam }\end{array}$ & $\begin{array}{l}3.79 \\
2.83\end{array}$ & $\begin{array}{l}.20 \\
.23\end{array}$ & $\begin{array}{l}6.62 \\
3.91\end{array}$ & $\begin{array}{l}.37 \\
.41\end{array}$ & $\begin{array}{l}8.79 \\
5.12\end{array}$ & $\begin{array}{l}.36 \\
.52\end{array}$ & $\begin{array}{l}3.54 \\
2.71\end{array}$ & $\begin{array}{l}.26 \\
.25\end{array}$ & $\begin{array}{l}4.92 \\
3.21\end{array}$ & $\begin{array}{l}.40 \\
.24\end{array}$ & $\begin{array}{l}4.92 \\
3.17\end{array}$ & $\begin{array}{l}.38 \\
.37\end{array}$ \\
\hline \multicolumn{13}{|c|}{ Delayed Recall } \\
\hline $\begin{array}{l}\text { Placebo } \\
\text { Diazepam }\end{array}$ & $\begin{array}{l}2.08 \\
0.92\end{array}$ & $\begin{array}{l}.31 \\
.27\end{array}$ & $\begin{array}{l}4.54 \\
1.58\end{array}$ & $\begin{array}{l}.38 \\
.33\end{array}$ & $\begin{array}{l}5.58 \\
2.54\end{array}$ & $\begin{array}{l}.38 \\
.55\end{array}$ & $\begin{array}{l}1.42 \\
0.46\end{array}$ & $\begin{array}{l}.23 \\
.26\end{array}$ & $\begin{array}{l}1.92 \\
0.62 \\
\end{array}$ & $\begin{array}{l}.34 \\
.14\end{array}$ & $\begin{array}{l}3.00 \\
1.00\end{array}$ & $\begin{array}{l}.39 \\
.20 \\
\end{array}$ \\
\hline
\end{tabular}


acquisition of information in LTM, then, as the role of LTM increases, drug effects should become more apparent-exactly as observed.

\section{GENERAL DISCUSSION}

The results of the present experiments again demonstrate that memory is influenced strongly by diazepam. Both free recall and delayed recall consistently revealed marked impairment due to diazepam. More importantly, the present results strongly suggest that diazepam operates on memory by impeding the permanent acquisition of new information, for example, by impairing the transfer of information from STM to LTM, while leaving STM and retrieval from LTM intact. Several aspects of the data support the contention that it is a LTM and not a STM process that is adversely affected. Analysis of the serial position curves demonstrated that diazepam impairs recall of only the early and middle items of the list. Recall of the final, or STM, items was virtually identical in drug and nondrug subjects. However, when the contribution of STM was eliminated, as in the delayed-free-recall task, drugged subjects displayed impaired recall across the whole serial position curve. In addition, with the exception of rate of presentation, variables that affect LTN more strongly than STM were found to be less potent for diazepam subjects than for placebo subjects.

Our second point, that diazepam does not impair retrieval from LTM, is best illustrated by the data from delayed free recall. Not only were drugged subjects not impaired in their recall of the predrug practice list, but in both Experiments 1 and 2 they actually recalled the predrug list better than did the placebo subjects. This is in marked contrast to what would be expected if recall following diazepam administration were state dependent, as might be anticipated given diazepam's ability to alter subjective moods (Ghoneim \& Mewaldt, 1975, 1977; Hinrichs et al., 1982).

The present results suggest that, in order to test for the cognitive impairment caused by diazepam, the most sensitive diagnostic tool would involve a memory task that minimized the contribution of STM and maximized the contribution of LTM. Thus, an appropriately designed test would test both immediate and delayed retention of a relatively long list of highly meaningful words. In addition, in immediate recall, the serial position curve should be closely analyzed.

A final point is worth making. A number of psychologists have become uncomfortable with terminology that suggests that STM and LTM are separate, identifiable processes. Although we believe this approach still has explanatory power, and, in particular, is consistent with the present data, it may not be the only way to interpret the memory effects caused by diazepam. However, the data do strongly support the necessity of maintaining a distinction between STM and LTM pro- cesses. The data suggest that there exists a process, whether it is called STM-LTM transfer, consolidation, schema formation, or whatever, that is vital to permanent acquisition of information, but that is not important for temporary registration of information or for its retrieval from memory. Furthermore, this process can be disrupted easily by diazepam, and by other pharmacological agents. The availability of such drugs may provide a potent tool for the investigation of memory processes.

\section{REFERENCES}

Atkinson, R. C., \& Shiffrin, R. M. Human memory: A proposed system and its control processes. In K. W. Spence \& J. T. Spence (Eds.), The psychology of learning and motivation (Vol. 2). New York: Academic Press, 1968.

Atkinson, R. C., \& Shiffrin, R. M. The control of short-term memory. Scientific American, 1971, 225(2), 82-90.

BAdDELEY, A. D., \& Hitch, G. Working memory. In G. H. Bower (Ed.), The psychology of learning and memory (Vol. 8). New York: Academic Press, 1974.

Birnbaum, I. M., \& Parker, E. S. Alcohol and human memory. Hillsdale, N.J: Erlbaum, 1977.

BjoRk, R. A., \& WhitTen, W. B. Recency-sensitive retrieval processes in long-term free recall. Cognitive Psychology, 1974, 6, 173-189.

Clarke, P. R. F., Eccersley, P. S., Frisgy, J. P., \& Thornton, J. A. The amnesic effect of diazepam (Valium). British Journal of Anaesthesia, 1970, 42, 690-697.

Crow, T. J., \& Grove-White, I. G. An analysis of the learning deficit following hyoscine administration to man. British Journal of Pharmacology, 1973, 49, 322-327.

Darley, C. F., Tinklenberg, J. R., Roth, W. T., Hollister, L. E., \& Atkinson, R. C. Influence of marijuana on storage and retrieval processes in memory. Memory \& Cognition, 1973, 1, 196-200.

DundeE, J. W., \& Pandit, S. K. Anterograde amnesic effects of pethidine, hyoscine and diazepam in adults. British Journal of Pharmacology, 1972, 4, 140-144.

Ghoneim, M. M., Hinrichs, J. V., \& Mewald, S. P. Doseresponse analysis of the behavioral effects of diazepam: I. Learning and memory. Psychopharmacology, in press.

Ghonem, M. M., \& MewaldT, S. P. Effects of diazepam and scopolamine on storage, retrieval, and organizational processes in memory. Psychopharmacologia, 1975, 44, 257-262.

Ghonetm, M. M., \& MewaldT, S. P. Studies on human memory: The interactions of diazepam, scopolamine, and physostigmine. Psychopharmacology, 1977, 52, 1-6.

Glanzer, M., \& Cunitz, A. R. Two storage mechanisms in free recall. Journal of Verbal Learning and Verbal Behavior, 1966, 5, 351-360.

Hinrichs, J. V., Mewaldt, S. P., Ghoneim, M. M., \& Berie, J. L. Diazepam and learning: Assessment of acquisition deficits. Pharmacology, Biochemistry \& Behavior, 1982, 17, 165-170.

KLATzKY, R. L. Human memory structures and processes (2nd ed.). San Francisco: Freeman, 1980.

Paivio, A., Yuille, J. C., \& Madigan, S. A. Concreteness, imagery, and meaningfulness values for 925 nouns. Journal of $E x$ perimental Psychology Monograph, 1968, 76(1, Pt. 2).

Parker, E. S., Birngaum, I. M., Weingartier, H., Hartley, J. T., Stillman, R. C., \& Wyatt, R. J. Retrograde enhancement of human memory with alcohol. Psychopharmacology, 1980, 69, 219-222.

Parker, E. S., Morihisa, J. M., Wyatt, R. J., Schwartz, 
B. L., Weingartner, H., \& Stillman, R. C. The alcohol facilitation effect on memory: A dose-response study. Psychopharmacology, 1981, 74, 88-92.

Sumby, W. H. Word frequency and the serial position effect. Journal of Verbal Learning and Verbal Behavior, 1963, 1, 443-450.

Thohndike, E. I.., \& LoRge, L. The teacher's word book of 30,000 words. New York: Columbia University Press, 1944.

Wavoh, N. C., \& Norman, D. A. Primary memory. Psychological Review, 1965, 72, 89-104.

\section{NOTE}

1. It is recognized that the Glanzer and Cunitz (1966) analysis employed here is not without its critics (e.g., Baddeley \& Hitch, 1974; Bjork \& Whitten, 1974). However, this analysis seems to provide the most consistent interpretation of results with diazepam.

(Manuscript received December 23, 1982; revision accepted for publication June 6,1983 .) 